International Journal of Engineering \& Technology, $7(3.34)(2018) 455-458$
International Journal of Engineering \& Technology
SPC
Website: www.sciencepubco.com/index.php/IJET
Research paper

\title{
Thermal Properties Characterization of Glass Fiber Hybrid Polymer Composite Materials
}

\author{
${ }^{1}$ Gurushanth B Vaggar, ${ }^{2}$ S C Kamate, ${ }^{3}$ Pramod V Badyankal \\ ${ }^{I}$ Department of Mechanical Engineering, Alva's Institute of Engineering and Technology, Mijar-574225, \\ VTU, Belagavi, Karnataka state, India \\ Principal, Hirasugar Institute of Technology, Nidasoshi, VTU, Belagavi. \\ Karnataka state, India \\ ${ }^{3}$ Department of Mechanical Engineering, AIET, Mijar-574225, \\ VTU, Belagavi, Karnataka state, India

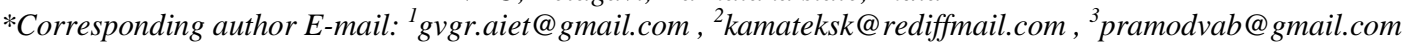

\begin{abstract}
In the current work characterization of thermal properties are find out to the prepared specimens of silicon filler hybrid composite materials (silicon filler glass - fiber chop strand). The specimens were prepared by hand layup followed by compression molding machine by non-heating molding technique. Thermal conductivity (K), Coefficient thermal expansion (CTE) and Thermal gravimetric analysis (TGA) are found by composite slab method and by thermal muffler oven in a laboratory. The guard heater is used to supply heat which is measured by voltmeter and ammeter. Thermocouples are placed between the interface of the copper plates and the specimen of silicon filled hybrid polymer composite material (HPC), to read the temperatures. By the experimental readings it is found that the K of silicon filler hybrid composite material directly proportional to the $\%$ of silicon fillers for the different trails. The CTE inversely varies with $\%$ of silicon fillers and in thermal gravimetric analysis the failure of material takes place at $300^{\circ} \mathrm{C}$ for a time of 20 minutes and also reduction in mass of silicon inserted hybrid composite material. From the results it has been concluded that the considerable enhance in thermal conductivity with negligible decrease in CTE and increase in thermal resistivity of hybrid composite materials.
\end{abstract}

Keywords: Thermal conductivity (K), Coefficient of Thermal Expansion (CTE), Thermal Gravimetric Analysis (TGA), Silicon.

\section{Introduction}

The polymer composites are the solution for low density high strength materials as compared to the metals and alloy metals. Further the polymer composites found failure under variable temperature conditions in different applications like military weapons, medical instruments, Automobile sectors and Aerospace body building etc. As a solution to this problem, hybridisation of reinforcements is tried in the polymer composites, known as hybrid polymer composites [HPC]. In regular polymer composites by adding small percentage of filler materials which will vary the overall thermal properties and try to make hybrid polymer composites stable under variable temperature conditions without altering the strength of polymer composite materials.

\subsection{Thermal Properties.}

The following thermal properties, 1) Thermal conductivity, 2) Coefficient of thermal expansion, and 3) Thermo gravimetric analysis are found experimentally and specimens and experimental setups are prepared as per the ASTM standards. Thermal properties of any materials decides withstanding and sustainability of that material under variable temperature conditions it may be high temperature or low temperature.
Thermal Conductivity: The measurements of $\mathrm{K}$ carried out under variable heat inputs at ATP condition. According to ASTM E1530 circular slab type HPC specimen diameter 150 $\mathrm{mm}$ and thickness $5 \mathrm{~mm}$ to $10 \mathrm{~mm}$ are used as shown in figure 1 . A known value of heat is applied from one side of the composite slab wait till the system reach steady state, the temperature of each interface surfaces were measured by thermocouples. Thermal conductivity determined by using one-dimensional Fourier's law of conduction equation. The conduction equation can be stated as "The rate of heat conduction in a given direction is proportional to the temperature gradient in that direction". This statement can be represented by equation
$Q=-K A$
$\frac{\mathrm{dT}}{\mathrm{dX}}$
- KA
$\frac{(\mathrm{T} 1-\mathrm{T} 2)}{\mathrm{L}}$

Where,

$\mathrm{Q}=$ Heat Supplied (W).

$\mathrm{K}=$ Thermal conductivity $\left(\mathrm{W} / \mathrm{m}^{\circ} \mathrm{C}\right)$.

$\mathrm{A}=$ Area $\left(\mathrm{m}^{2}\right)$.

$\mathrm{L}=$ Thickness of the HPC specimen (m).

$\mathrm{T}_{1}=$ Temperature of lower interface surface of HPC

Specimen $\left({ }^{\circ} \mathrm{C}\right)$.

$\mathrm{T}_{2}=$ Temperature of upper interface surface of HPC Specimen $\left({ }^{\circ} \mathrm{C}\right)$. 
$\frac{\mathrm{dT}}{\mathrm{dX}}=$ Temperature gradient $\left({ }^{\circ} \mathrm{C} / \mathrm{m}\right)$.

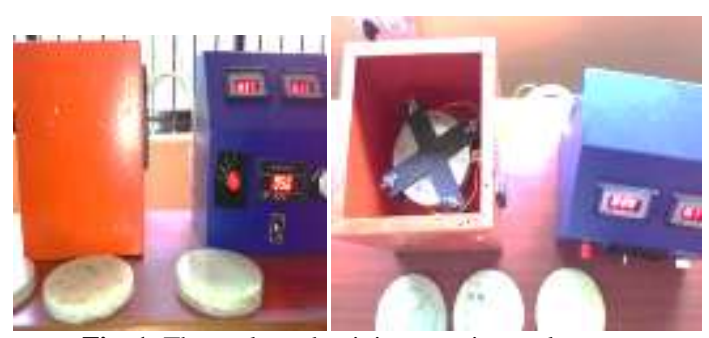

Fig. 1: Thermal conductivity experimental set up

Coefficient of Thermal Expansion (CTE): Most solid materials expand by heating and contract when cooled. Thermal expansion is a property of a material is indicative of the extent to which a material expands upon heating. The change in length with temperature for a solid material may be expressed as follows

$\frac{l_{\mathrm{f}}-l_{0}}{l_{0}}=\alpha_{1}\left(\mathrm{~T}_{\mathrm{f}}-\mathrm{T}_{0}\right)$

$\frac{\Delta l}{l_{0}}=\alpha_{1} \Delta \mathrm{T}$

Where,

$l_{\mathrm{o}}=$ Initial length

$l_{\mathrm{f}}=$ Final length

$\mathrm{T}_{\mathrm{o}}=$ Initial temperature

$\mathrm{T}_{\mathrm{f}}=$ Final temperature

$\alpha_{1}=$ linear coefficient of thermal expansion

The CTE test conducted to HPC specimens had length $90 \mathrm{~mm}$ and thickness $5 \mathrm{~mm} \& 10 \mathrm{~mm}$. The CTE tests were done for the temperature range of $25^{\circ} \mathrm{C}$ to $90^{\circ} \mathrm{C}$ using temperature controlled muffler furnace. The HPC specimens heated from room temperature to $90^{\circ} \mathrm{C}$ in the muffler furnace and kept at $90^{\circ} \mathrm{C}$ for 10 minute. CTE calculated by

$\alpha_{1}=\frac{\Delta l}{\Delta \mathrm{T} l_{0}}$

Where,

$\alpha_{1}=$ Coefficient of Thermal Expansion $\left(1 /{ }^{\circ} \mathrm{C}\right)$

$l_{0}=$ Original length of the $(\mathrm{mm})$

$\Delta \mathrm{T}=$ Temperature change $\left({ }^{\circ} \mathrm{C}\right)$

$\Delta l=$ Change in length of the sample $(\mathrm{mm})$

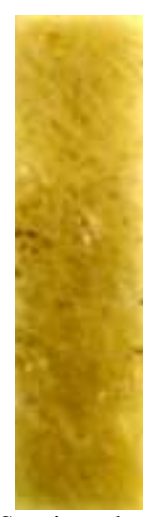

Fig. 2a: Specimen before CTE Test

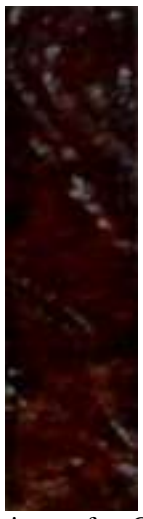

Fig. 2b: Specimen after CTE Test
Thermo Gravimetric Analysis (TGA): Thermo gravimetric analysis is one of the method thermal analysis in which the changes in physical and chemical properties of specimens measured with reference to the increase in temperature. The TGA test carried out to the square specimens of size $50 \mathrm{~mm} x$ $50 \mathrm{~mm}$ and thickness $5 \mathrm{~mm}$ and $10 \mathrm{~mm}$. The TGA tests were performed over the temperature range of $30^{\circ} \mathrm{C}$ to $300^{\circ} \mathrm{C}$ using temperature controlled muffle furnace. Specimens heated from room temperature to $300^{\circ} \mathrm{C}$ in the muffler furnace and kept at $300^{\circ} \mathrm{C}$ for 20 minutes. After heating specimens check for decompose of hybrid polymer composites and \% of loss material in weight is calculated. Figure 3 a shows specimen before TGA test and figure $3 \mathrm{~b}$ shows the decomposed specimen after TGA test.
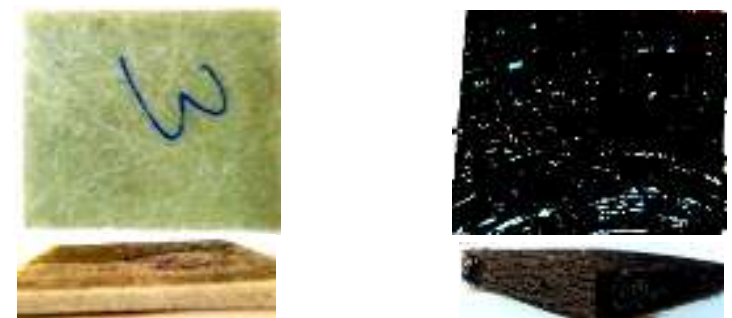

Fig. 3a: Specimen before TGA Test Fig. 3b: Specimen after TG Test

\section{Method to Prepare Hybrid Polymer Composites}

Machine moulding is used to prepare hybrid polymer composites by hand layup method. Mould box is prepared as per the size of the HPC with the proper mixture of resin hardener and filler particles pasted on glass fiber layups then pressure applied on mould by using SANTAC compression moulding machine allowed cure for 24 hours under normal atmospheric conditions. This method of preparing hybrid polymer composites is the simplest and economical than other methods.

\section{A. Specimen Compositions}

The different specimens with material compositions are given below in table I, $5 \mathrm{~mm}$ thickness (GE5) and $10 \mathrm{~mm}$ thickness specimens (GE10).

Table I: Designation of Hybrid Polymer Composite Materials

\begin{tabular}{|l|l|l|l|l|}
\hline \multirow{2}{*}{$\begin{array}{l}\text { Material } \\
\text { Designation }\end{array}$} & \multicolumn{4}{|c|}{ Weight Quantity in Grams } \\
\cline { 2 - 5 } & Silicon & $\begin{array}{l}\text { E-Glass } \\
\text { Fiber }\end{array}$ & $\begin{array}{l}\text { Epoxy } \\
\text { Resin }\end{array}$ & Hardener \\
\hline GE5 & 0 & 342 & 303.75 & 33.75 \\
\hline GE5SI5 & 16.87 & 342 & 288.567 & 32.063 \\
\hline GE5SI10 & 33.75 & 342 & 273.375 & 30.375 \\
\hline GE10 & 0 & 684 & 607.75 & 67.5 \\
\hline GE10SI5 & 33.75 & 684 & 577.125 & 64.125 \\
\hline GE10SI10 & 67.5 & 684 & 546.75 & 60.75 \\
\hline
\end{tabular}

\section{Results and Discussion}

Characterization of thermal properties K, CTE, and TGA for different composition hybrid polymer composite materials are shown in tables II-IV and their variations with respect to different specimens are shown in figures 4-6 respectively.

\subsection{Thermal Conductivity}

Thermal conductivity of hybrid polymer composite (HPC) of $10 \%$ $\mathrm{SiC}$ filler gives the maximum value of $0.1687 \mathrm{~W} / \mathrm{m}{ }^{\circ} \mathrm{C}$ for $5 \mathrm{~mm}$ 
thickness HPC material and $0.1976 \mathrm{~W} / \mathrm{m}$ C for $10 \mathrm{~mm}$ thickness HPC material. In figure 4 it shows that the thermal conductivity value increases as the percentage of silicon filler material increases.

Table Ii: Comparison of Thermal Conductivity

\begin{tabular}{|l|l|}
\hline $\begin{array}{l}\text { Hybrid Polymer Composite } \\
\text { material (HPC) }\end{array}$ & $\begin{array}{l}\text { Thermal conductivity } \\
\left(\mathbf{W} / \mathbf{m}^{\circ} \mathbf{C}\right)\end{array}$ \\
\hline GE5 & 0.1194 \\
\hline GE5SI5 & 0.1432 \\
\hline GE5SI10 & 0.1687 \\
\hline GE10 & 0.1773 \\
\hline GE10SI5 & 0.1887 \\
\hline GE10SI10 & 0.1976 \\
\hline
\end{tabular}

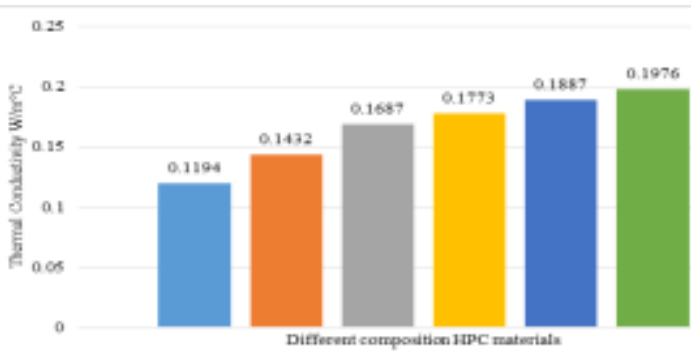

=aEs =aEssis =aEssio =aE10 =aEiosts =aEtostno

Fig. 4: Comparison of Thermal Conductivity of HPC materials

\section{B. Coefficient of Thermal Expansion (CTE)}

Coefficient of Thermal Expansion of hybrid polymer composite [HPC] of $10 \% \mathrm{SiC}$ filler gives the minimum value of $6.36 \times 10^{-6}$ $I^{\circ} \mathrm{C}$ for $5 \mathrm{~mm}$ thickness HPC material and $5.44 \times 10^{-6} /^{\circ} \mathrm{C}$ for 10 $\mathrm{mm}$ thickness HPC material. As the percentage of silicon filler material increases the coefficient of thermal expansion decreases for both $5 \mathrm{~mm}$ and $10 \mathrm{~mm}$ thickness HPC specimens. The thermal conductivity of silicon is greater than that of epoxy resin hence the coefficient of thermal expansion of hybrid polymer composite decreases with increase in percentage of silicon.

Table Iii: Comparison of Coefficient of Thermal Expansion (CTE)

\begin{tabular}{|l|l|}
\hline $\begin{array}{l}\text { Hybrid Polymer Composite } \\
\text { material (HPC) }\end{array}$ & $\begin{array}{l}\text { Coefficient of Thermal } \\
\text { Expansion }\left(/{ }^{\circ} \mathbf{C}\right)\end{array}$ \\
\hline GE5 & $9.1 \times 10^{-6}$ \\
\hline GE5SI5 & $8.18 \times 10^{-6}$ \\
\hline GE5SI10 & $6.36 \times 10^{-6}$ \\
\hline GE10 & $7.2423 \times 10^{-6}$ \\
\hline GE10SI5 & $6.36 \times 10^{-6}$ \\
\hline GE10SI10 & $5.44 \times 10^{-6}$ \\
\hline
\end{tabular}

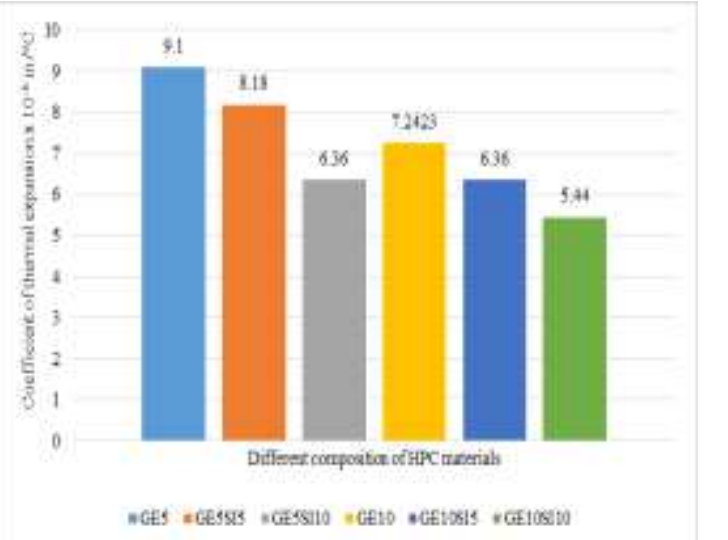

Fig. 5: Comparison of Coefficient of Thermal Expansion of Hybrid Polymer Composite Materials

\section{Thermo Gravimetric Analysis (TGA):}

From Thermo gravimetric analysis test it has been observed that the percentage weight loss of HPC material is more for $10 \% \mathrm{SiC}$ filler material and less for $5 \% \mathrm{SiC}$ filler material. Figure 6 shows in Thermo Gravimetric Analysis test the percentage of weight loss is more in $5 \mathrm{~mm}$ thickness HPC material as compared to 10 $\mathrm{mm}$ thickness HPC material. High percentage of weight loss indicates that the high decompose of HPC materials occurs which gives an exact temperature up to which the failure of HPC materials takes place.

The TGA test conducted at temperature $300^{\circ} \mathrm{C}$ which is higher than the glass transition temperature (GST) of epoxy resin, thermal conductivity of silicon is higher than glass fiber and epoxy resin which causes the hybrid polymer composite sustain higher temperature than that of glass transition temperature of polymers, hence individually there is no effect of various percentage addition of glass fiber and silicon on glass transition temperature of epoxy resin, GST of hybrid polymer composite improves as compared to neat polymer composites. High thermal conductivity of silicon cause the higher weight loss of $\mathrm{Si}$ inserted samples it is increasing with increase in $\mathrm{Si}$ content because GST of polymers much less than sustainable temperature of $\mathrm{HPC}\left(300^{\circ} \mathrm{C}\right)$

Table IV: Comparison of \% Weight Loss in Material (TGA)

\begin{tabular}{|l|l|}
\hline Hybrid Polymer Composite material & \% Weight loss \\
\hline GE5 & 6.67 \\
\hline GE5SI5 & 8.33 \\
\hline GE5SI10 & 9.375 \\
\hline GE10 & 2.33 \\
\hline GE10SI5 & 3.22 \\
\hline GE10SI10 & 4.65 \\
\hline
\end{tabular}

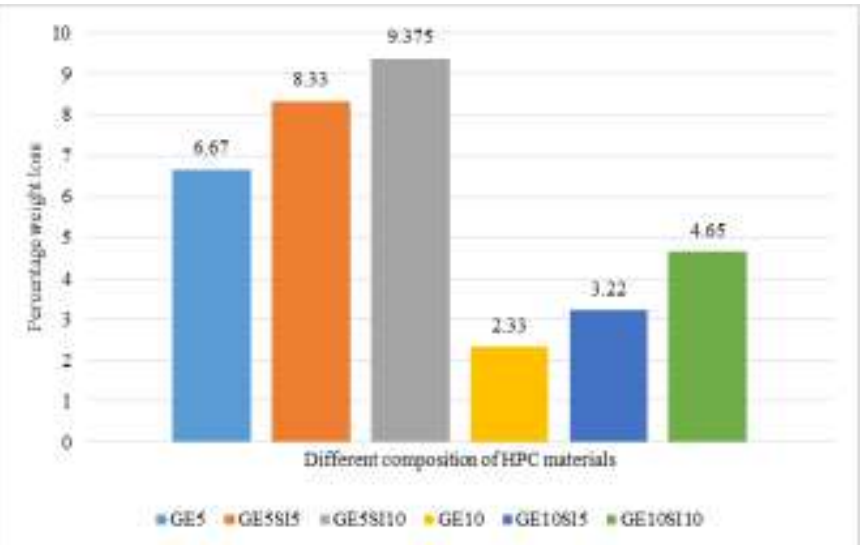

Fig. 6: Comparison of Percentage of Weight Loss of HPC Materials

\section{Conclusions}

Thermal conductivity of hybrid polymer composite materials increases as the percentage of $\mathrm{SiC}$ filler material increases and as thickness of specimen increases the thermal conductivity also increases. The coefficient of thermal expansion decreases as the percentage of filler material $\mathrm{SiC}$ increases. By Thermo gravimetric analysis it shows that the specimens gets decomposed around $275^{\circ} \mathrm{C}$ to $280^{\circ} \mathrm{C}$. The loss of weight also observed during decomposition of specimens, it varies from $2.33 \%$ to $9.375 \%$. The percentage weight loss increases as the percentage of filler material $\mathrm{SiC}$ increases. With the above results it is concluded that hybrid polymer composite materials can withstand high temperatures up to $300^{\circ} \mathrm{C}$. Silicon can be used as filler material in GFER composites successfully. 


\section{References}

[1] Basava T, A N Harirao. "Development of graphite particles filled epoxy resin composite material and its erosive wear behaviour". AMAE Int. J. on Manufacturing \& material science, Vol.01, No.02, November 2011.

[2] Th. Schubert, T. Weibgarber and B. Kieback. "Fabrication and properties of copper/carbon composites for thermal management applications". Advanced materials research Vol. 59 169-172, 2009.

[3] Moran Wanga, Qinjun Kang b, Ning Pan. "Thermal conductivity enhancement of carbon fiber composites". Applied thermal engineering 2008 .

[4] Dilek Kumlutas, Ismail H, Tavaman, M. Turhan Coban "Thermal conductivity of particle filled polyethylene composite materials". Elsevier Composites Science and Technology 63, 113 $-1172003$.

[5] Sudarisman, I.J. Davies, H. Hamada. "Compressive failure of unidirectional hybrid fibre-reinforced epoxy composites containing carbon and silicon carbide fibres". Compos. Part A, 38(3) 1070 -1074 2007.

[6] Watthanaphon Cheewawuttipong, Daisuke Fuoka, Shuich Tanoue, Hideyuki Uematsu, and Yoshiyuki Iemoto. "Thermal and mechanical properties of polypropylene/boron nitride composites". Elsevier energy procedia 34, 808 - 817, 2013.

[7] Alok Agrawal, and Alok Satapathy. "Development of a heat conduction model and investigation on thermal conductivity enhancement of AlN/Epoxy composites". Elsevier procedia engineering 51, 573-578, 2013.

[8] Ravi Kumar B N, Ananda.G.K, Shivaappa.D, Mahesh.H.R. "Effect of fillers on thermal and fire resistance properties of $E$ glass epoxy composites". International journal of mechanical engineering research \& applications (IJMERA) Vol. 1 Issue 4 September - 2013 .

[9] Krishnamachar Srinivas, Mysore Siddalingappa Bhagyashekar. "Thermal conductivity enhancement of epoxy by hybrid particulate fillers of graphite and silicon carbide". Journal of minerals and materials characterization and engineering, Vol.3, 76-84, 2015

[10] Dr.Jawad Kadhim Uleiwi, Sura Salim. "Study of thermal characteristics of a composite specimen experimentally and by using finite element method". Eng. \& Tech. Vol.26, No4, 2008.

[11] MaximeVilliere, Damien Lecointe, Vincent Sobotka, Nicolas Boyard, Didier Delaunay. "Experimental determination and modelling of thermal conductivity tensor of carbon/epoxy composite". Elsevier composites, part A46, 60-68, 2013.

[12] ZHENG Jing, SONG Wen-juan, MA Guang, JIA Zhi-hua "Thermal expansion and mechanical properties of $A l / S i$ composites fabricated by pressure infiltration" Science press trans. nonferrous Met. Soc. China 17, s326-s329, 2007.

[13] Malla Surya Teja, M V Ramana, D Sriramulu3and C J Rao. "Experimental investigation of mechanical and thermal properties of sisal fibre reinforced composite and effect of SiC filler material". IOP Conf. Series: Materials science and engineering 149, 012095 doi:10.1088/1757-899X/149/1/012095, 2016.

[14] K. Devendra and T. Rangaswamy. "Thermal conductivity and thermal expansion coefficient of GFRP composite laminates with fillers". ISSN: 2320-2491, volume 2, N0. 5, August-September 2013.

[15] Yang Hua, Qing-Qing Ni, Atsuhiko Yamanaka, Yoshihiko Teramoto and Toshiaki Natsuki. "The development of composites with negative thermal expansion properties using high performance fibers". Advanced composite materials 20, 463-475, 2011.

[16] Tahir Ahamad, Rafiq Ahamad, Muhammad Kamran, Bambang Wahjoedi, Imran Ahakoor, Faraz Hussain, Farhad Riaz, Zuhaib Jamil, Sirjeel Isaac, Qaiser Ashraf. "Effect of thal silica sand nanoparticles and glass fiber reinforcement on epoxy-based hybrid composite". Iran polym J 24: 21-27, 2015.

[17] Brian Y. Lattimer, Jason Ouellette. "Properties of composite materials for thermal analysis involving fires" Elsevier composites, part A37 1068-1081, 2006. 